already a minimum age-limit for the purchase of tobacco. But there is nothing whatsoever to stop children from buying thei cigarettes from automatic machines which are to be found in abundance.

If the Government is serious in its wish to deter people from smoking, it would be a very simple measure to ban cigarette machines completely. Such a move would have the virtue of harming nobody (except the manufacturers of cigarettes and automatic machines) while producing the maximum potential benefits.-I am, etc.,

\section{MYER GOLDMAN.}

\section{X-ray Department,
Fazakerley Hospital, Liverpool.}

\section{Childhood Bronchitis}

SIR,-The survey of the origins of childhood bronchitis by Dr. J. R. T. Colley and Professor D. D. Reid (25 April, p. 213) throws light on the important question of the high incidence of chronic bronchitis in Britain. They discuss two possible reasons for the excess morbidity in South Wales.

I suggest a third possible reason. It has been shown that not only do coal miners have a relatively high incidence of chronic bronchitis, but their wives do also. Migh this not be the result of excessive heating and reduced humidity of the air in their homes in winter as a result of an excellent supply of coal? A number of visits to miners' homes in the winter has impressed me with this possibility.-I am, etc.,

\section{Pinderfields General Hospital,
Wakefield, Yorks.}

\section{J. K. ScotT.}

\section{Relapse after Standard Treatment of Malaria}

SIR,-Radical cure of $P$. vivax infections (elimination of the exoerythrocytic cycle) is thought to be achieved in the majority of patients from most parts of the world by the administration of an 8-aminoquinoline such as primaquine diphosphate given in standard dosage $(15 \mathrm{mg}$. base daily for 14 days). However, many physicians are aware that standard doses do not effect a cure in all patients, although in regions of malarial endemicity many cases are often unreported since relapse following treatment is difficult to distinguish from re-infection.

A West Pakistani male, aged 30 years, arrived in the United Kingdom in December, 1966, having briefly visited Iran, Iraq, Syria, Turkey, and Saudi Arabia en route. He was admitted to the Hospital for Tropical Diseases in June, 1967, with a 10-day history of fever, rigors, headache, nausea, and vomiting. Clinical examination was normal except for a temperature of $104^{\circ} \mathrm{F}$. $\left(40^{\circ}\right.$ C. $)$ and tachycardia. A blood slide howed trophozoites of $P$. vivax. He was treated with a standard course of chloroquine $(600 \mathrm{mg}$ chloroquine base stat., $300 \mathrm{mg}$. base 6 hours later, and $300 \mathrm{mg}$. daily for 2 days) and rapidly became apyrexial. Primaquine diphosphate, $7 \cdot 5$ mg. twice daily, was then given. This was taken in hospital for the first four days, the remainder of the 14-day course being completed at home.

He remained well until September 1968 (15 months after treatment), when he was readmitted to hospital with a three-day history of fever and profuse sweating on alternate days $\mathrm{He}$ insisted that he had completed the course of primaquine prescribed in 1967, and that he had not been outside the United Kingdom in the intervening period. Examination again disclosed trophozoites of $P$. vivax in the peripheral blood. A standard course of chloroquine was prescribed, and he became apyrexial by the third day. A 14-day course of primaquine was given and he was discharged from hospital after having taken the drug for three days under observation. $\mathrm{He}$ has remained well up to the time of writing.

It seems that the second parasitaemia in this patient was most probably due to the failure of primaquine therapy in 1967 to eradicate the experythrocytic cycle, al though the patient had been given $15 \mathrm{mg}$ primaquine diphosphate daily for two weeks, which is a standard course of treatment. ${ }^{1}$ Although the primaquine had been taken under observation for four days only there is no reason to doubt the patient's asser tion that he had completed the full 14 days course. The importance of this case report is that it underlines the fact that not all case of $P$. vivax are cured by standard courses of primaquine even when such cases are from regions of the world where primaquineresistance has not been reported previously. Although clinicians in the tropics are familiar with the problems of the treatment of malarial infections, many practitioners in the United Kingdom are no aware that treatment does not effect a radical cure in $100 \%$ of patients.

Thanks are due to Professor A. W. Woodruf and Dr. H. A. K. Rowland for permission to report this case, and to Dr. D. S. Ridley and Mr. A. V. H. Allen for carrying out the parasitological investigations.

-I am, etc.,

\section{R. A. WISEMAN.}

\section{Clinical Research Department, \\ Imperial Chemical Industries Ltd., Alderley Park, Cheshire.}

\section{REFERENCE}

Manson's Tropical Diseases, ed. P. H. Manson

Bahr, 15th edn., p. 86. London, Cassell, 1960.

\section{Defects in the Diaphragm}

SIR,-With reference to the medica memorandum (11 April, p. 94) on acute hydrothorax complicating peritoneal dialysis it must be in the memory of those ches physicians who used artificial pneumoperitoneum in the treatment of pulmonary tuberculosis that occasionally distressing symptoms developed during the insufflation, owing to air passing through defects in the diaphragm and causing a pneumothorax. It is not surprising that a hydrothorax could be similarly produced, and those physicians who do this work should certainly bear the possibility in mind.-I am, etc.

\section{Chest Clinic, \\ orbay Hospital,}

\section{Falsely High Potassium Values}

SIR,-The report on falsely high potassium values in patients with hyperaldosteronism (4 April, p. 18) by Dr. J. J. Brown and others also highlighted the erro implicit in measuring serum levels of potassium. We would like to concur with the authors that this is not sufficiently well known, and to add some details of a case of myelofibrosis in which spurious hyperkalaemia endangered the management.

In June 1968 a 64-year-old lady was investigated in Lewisham Hospital for the cause of a leucoerythroblastic anaemia with congestive heart failure and splenomegaly. The diagnosis was made on the repeated failure to aspirate bone marrow and the typical findings in the bone biopsy and from the radioactive iron studies. Splenectomy was undertaken in view of the raised plasma volume $(76 \mathrm{ml} . / \mathrm{kg}$.), evidence of increased splenic red cell destruction, thrombocytopenia, and considerable local discomfort. The serum potassium was $4.3 \mathrm{mEq} / 1$. prior to the operation. The platelet count rose following the splenectomy reaching a maximal level of $1,100,000 / \mathrm{cu} . \mathrm{mm}$. one month later and thereafter did not fall below 750,000/cu.mm

The patient remained oedematous despite a fall in plasma volume (46 ml. $/ \mathrm{kg}$.), and varying and increasing diuretic regimens were tried. The serum potassium increased to levels of between 6.0-7.0 $\mathrm{mEq} / 1$., and potassium supplements were discontinued in October 1968. Seven weeks later the patient complained of weakness and lassitude, but the clinical diagnosis of hypokalaemia was apparently contradicted by the serum potassium of $7.2 \mathrm{mEq} / 1$. Interpretation of the E.C.G. was made difficult by ischaemic changes, and a further potassium level deter mination was made using rapidly separated heparinized plasma resulting in a value of 2.4 $\mathrm{mEq} / \overline{\mathrm{I}} \mathrm{A}$ base line urinary estimation followed and oral potassium supplements were restarted. The urinary excretion rose from the low level of $15 \mathrm{mEq} / 24 \mathrm{hr}$. to $69 \mathrm{mEq} / 24 \mathrm{hr}$. Subsequent electrolyte determinations were made on heparizined blood.

Serum can become enriched in vitro by potassium leakage not only from red cells but also white cells ${ }^{1}$ and platelets. ${ }^{2}$ In the absence of haemolysis and leucocytosis the major contribution appears to be released from platelets during clotting. This potassium leak may be accentuated in myelofibrosis. Even in healthy individuals with normal counts there is a significant difference between plasma and serum levels. In our series of normal serum and plasma potassium values taken from 50 blood donors the difference lies between the range given by Brown et al., and that of Pfleiderer et al., with a mean rise of $0.35 \mathrm{mEq} / 1$. and a range of $0.05-0.60 \mathrm{mEq} / 1$.

If the results are plotted as a histogram of plasma and serum levels (Fig.) there is a considerable overlap, which may account for the lack of comment in commonly used textbooks of laboratory medicine with one recent exception. ${ }^{4}$ However, it would seem that there is a case for at least a mention of spurious hyperkalaemia.-We are, etc.,

O. H. B. GYDE.

T. M. L. PRICE.

D. N. WHITMORE.

Lewisham Hospital

London S.E.13.

\section{REFERENCES}

Wills, M. R., and Fraser, I. D., fournal of Clinical Pathology, 1964, 17, 649

2 Hartman, R. C., Auditore, J. V., and Jackson, 37, 699 .

Pfleiderer, T Otto, P., and Hardegg, W., Klinische Wochenschrift, 37, 39.

- Gambino, S. R., in Todd-Sandford Clinical Diagnosis by Laboratory Methods, 14th ed. p. 645. I. Davidsonn a 